\title{
Testing for the induction of anti-herbivory defences in four Portuguese macroalgae by direct and water-borne cues of grazing amphipods
}

\author{
Hee Young Yun $\cdot$ Joana Cruz $\cdot$ Michaela Treitschke $\cdot$ \\ Martin Wahl $\cdot$ Markus Molis
}

Received: 16 October 2006/Revised: 21 February 2007/Accepted: 1 March 2007/Published online: 4 April 2007

(C) Springer-Verlag and AWI 2007

\begin{abstract}
Herbivory is a key factor in regulating plant biomass, thereby driving ecosystem performance. Algae have developed multiple adaptations to cope with grazers, including morphological and chemical defences. In a series of experiments we investigated whether several species of macroalgae possess anti-herbivore defences and whether these could be regulated to demand, i.e. grazing events. The potential of direct grazing on defence induction was assessed for two brown (Dictyopteris membranacea, Fucus vesiculosus) and two red seaweeds (Gelidium sesquipedale, Sphaerococcus coronopifolius) from São Rafael and Ria Formosa, Portugal. Bioassays conducted with live algal pieces and agar-based food containing lipophilic algal extracts were used to detect changes in palatability after exposure to amphipod attacks (=treatment phase). Fucus vesiculosus was the only species significantly reducing palatability in response to direct amphipod-attacks. This pattern was observed in live $F$. vesiculosus pieces and agarbased food containing a lipophilic extract, suggesting that lipophilic compounds produced during the treatment phase were responsible for the repulsion of grazers. Water-borne
\end{abstract}

Communicated by H.-D. Franke.

H. Y. Yun · M. Molis ( $\square)$

Biologische Anstalt Helgoland,

Alfred-Wegener-Institute for Polar and Marine Research, Marine Station, Kurpromenade 201, 27498 Helgoland, Germany e-mail: markus.molis@awi.de

J. Cruz

Centro de Ciências do Mar do Algarve, FCMA, Universidade do Algarve, Campus de Gambelas, 8005-139 Faro, Portugal

M. Treitschke - M. Wahl

IFM-GEOMAR, Leibniz-Institute for Marine Science,

Düsternbrooker Weg 20, 24105 Kiel, Germany cues of grazed $F$. vesiculosus as well as non-grazing amphipods also reduced palatability of neighbouring conspecifics. However, this effect was only observed in live tissues of $F$. vesiculosus. This study is the first to show that amphipods, like isopods, are capable to induce anti-herbivory defences in $F$. vesiculosus and that a seasonally variable effectiveness of chemical defences might serve as a dynamic control in alga-herbivore interactions.

Keywords Amphipods - Anti-herbivory response · Induction · Macroalga-grazer interaction · Portugal · Seaweeds

\section{Introduction}

Herbivory is a key factor for controlling biomass accrual and community structure of macroalgae (Hay and Fenical 1988; Hay 1991; Cyr and Pace 1993) and, thus, affecting a central ecosystem service. Depending on the food web structure of a system, meso-herbivores (Brawley 1992) may benefit from the presently observed overexploitation of predatory fish (Myers and Worm 2003), which would enhance their impact on macroalgae. Despite their low mobility and consumption rates relative to macro-herbivores (e.g. fishes), meso-herbivores (e.g. amphipods) due to their elevated numbers and more site-bound life histories may shape species composition of macroalgal communities (Brawley and Adey 1981; Duffy and Hay 2000).

In contrast to macro-herbivores, meso-herbivores may use algae as both food and habitat because they consume only part of an algal individual (Hay et al. 1987). This more lasting but less destructive association should influence algal responses to meso-herbivory. Algae can actively deter herbivores morphologically and/or chemi- 
cally (Hay 1996; Cronin 2001). To cope with a typically more sudden, more intense but less permanent attack by macro-herbivores such as fishes, a constitutive defence may be optimal. In contrast, meso-herbivores consume smaller portions of their food over longer time spans, which could favour the selection for defences that are adjusted to grazing pressure (inducible defence). In an evolutionary context, macroalgae displaying inducible anti-herbivory defences may have a selective advantage over constitutively defended algae for several reasons. First, the risk of self-intoxication is reduced because the production and storage of potentially harmful chemicals is minimised (Agrawal and Karban 1999). Second, algae with inducible defences represent a temporally and spatially variable ("moving") target to herbivores, exacerbating herbivore adaptations to defensive algal traits (sensu Karban et al. 1999). Third, meso-herbivores move from induced to non-induced algae, which in turn exposes them more to predators (Borell et al. 2004).

An induction of anti-herbivory defences is well documented for vascular plants (Karban and Baldwin 1997), but only limited evidence-essentially restricted to brown algae-exists for seaweeds. Present knowledge suggests that anti-herbivory defences in algae are a quite differential response. For instance, Pavia and Toth (2000) demonstrated that grazer identity matters as to whether defences were induced or not. Moreover, algal responses may be tissue-specific, when valuable algal parts, e.g. holdfasts, display constitutive and other tissues inducible defences (Taylor et al. 2002). Seasonal patterns of induction add further complexity to alga-grazer interactions (Molis et al. 2006). Induced defences were shown to be temporally and spatially variable. For example, the defence levels in $F$. vesiculosus were lowered to pre-grazed levels within 10 days (Hemmi et al. 2004). In addition, the repulsive response was not spreading to adjacent tissue (Hemmi et al. 2004). However, Toth and Pavia (2001) suggested that the information to defend may be propagated by water-borne cues within and between individual algae. To date only few studies have demonstrated the effects of water-borne cues in the context of inducing anti-herbivory defences in macroalgae (Toth and Pavia 2000; Rohde et al. 2004; Macaya et al. 2005). Knowledge on whether effective water-borne cues stem from the grazer or the alga is extremely scarce. Furthermore, little is known about the identity of chemical compounds that are induced during anti-herbivory responses.

The aim of this study was to test whether (1) direct grazer attacks induce defences in selected red and brown seaweeds, (2) water-borne cues from either conspecifics and/or grazers could induce anti-herbivory defences, and (3) the effects of the water borne cues might decrease, after grazing stopped.

\section{Materials and methods}

\section{Collection sites and organisms}

All algae and herbivores were collected at the intertidal rocky shores of São Rafael, Albufeira $\left(37^{\circ} 05^{\prime} \mathrm{N}, 8^{\circ} 15^{\prime} \mathrm{W}\right)$ and the lagoon-system Ria Formosa $\left(37^{\circ} 1^{\prime} \mathrm{N}, 7^{\circ} 55^{\prime} \mathrm{W}\right)$, Portugal. To ensure the ecological relevance of the research, study algae were selected by regional abundance and their supposed role as habitat engineers (large, bushy, perennial), and relevant herbivores were selected after assessing feeding preferences in pilot studies (data not shown). As a result, we chose two species each of red (Gelidium sesquipedale and Sphaerococcus coronopifolius) and brown seaweeds (Dictyopteris membranacea and Fucus vesiculosus). As herbivores, we selected an assemblage of three amphipod species (Gammarus insensibilis, Gamarella fucicola, and Cymadusa filosa) naturally associated with and feeding on the selected macroalgae at both collection sites. Hereafter algae are referred to by their generic names and herbivores as amphipods.

\section{Experimental set-up and design}

We conducted two induction experiments, one in July and one in September 2003. These were divided into either two (acclimation and treatment, July experiment) or three (additional recovery, September experiment) 2-week phases. First, the effects of herbivore attack on the induction of anti-herbivory defences in live algal pieces were assessed for all four selected species of macroalgae. Treatment effects, i.e. change in palatability, were identified by feeding assays, where after the treatment phase the consumers could choose between a grazed and a non-grazed algal piece. To test whether an observed induction was based on non-polar secondary metabolites, we conducted feeding assays with artificial food containing broad-spectrum DCM extracts. The effects of water-borne cues were assayed in the September experiment with only Fucus.

For the July experiment, five specimens of each algal species $(n=5)$ were collected and transferred in a cooler to the Marine Laboratory of Ramalhete, Faro, Portugal, within $2 \mathrm{~h}$ after collection on 18 July 2003. On the same day, all macroscopic epibionts were gently removed from all algae with a sponge. Six pieces (ca. $3 \mathrm{~g}$ per piece) of comparable tissue type were cut from each specimen. These six pieces were distributed at random between one control and one treatment aquarium (experimental units EUs), resulting in a total of 40 EUs ( 4 species $\times 5$ individuals $\times 2$ treatment levels) containing three genetically identical thallus pieces each. Each transparent plastic aquarium (2 1 volume) was individually supplied with a continuous, unidirectional flow of seawater from a 
reservoir directly connected to the coastal lagoon next to the marine station.

At the start of the July experiment, algal pieces remained for 14 days without consumers (acclimation phase) to adjust to cultivation conditions and to equalise possible differences in defensive traits, which may had been acquired by unknown grazing histories in the field. After acclimation, one (for Fucus and Dictyopteris), two (for Sphaerococcus), or three (for Gelidium) amphipod individuals were randomly drawn from the three-species mixture and added to each treatment EU and allowed to consume the macroalgae for 14 days, while no grazers were added to the control EUs (treatment phase). Thus individual study algae were exposed to one to three grazer species, but averaged over all replicates for a given algal species, the consumption quantified was due to the naturally occurring mixture of the three-amphipod species. Working with different consumer species within one treatment increases the scatter of results but reflects what is happening in the field. Grazer densities varied among algal species according to observed densities in the field in order to keep grazing pressure in our experiment comparable to natural levels of herbivory. At the end of the treatment phase, grazers were removed. The palatability of live algal pieces, and, when appropriate, artificial food was assessed in choice feeding assays (see below).

For the September experiment, seven Fucus specimens $(n=7)$ were collected in the Ria Formosa lagoon on 13 September 2003. All EUs were vertically divided by a mesh ( $1 \mathrm{~mm}$ mesh size) into equally sized up- and downstream compartments. Twenty pieces of comparable tissuetype were cut from single plants and five pieces each randomly allocated to the downstream compartments of four EUs at the beginning of the acclimation phase (7 plants $\times 4$ treatments $=28$ EUs total). Four different treatment levels were allocated to the EUs: (1) addition of amphipods to the downstream compartment (test for direct grazer attack), (2) addition of amphipods and Fucus pieces to the upstream compartment (test for water-borne cues from nearby grazed conspecific algae and/or grazing amphipods), (3) addition of amphipods to the upstream compartment (test for water-borne cues from non-grazing amphipods), and (4) no addition of amphipods or algae to the upstream compartment (control). At the end of the treatment phase, all herbivores were removed from the EUs as well as all Fucus pieces from the upstream compartments. Moreover, 2 algal pieces were randomly withdrawn from the downstream compartment of each EU and used for either multi-choice feeding assays of live pieces or agar-based food containing lipophilic Fucus extracts, respectively. Two of the other three algal pieces remained in the EUs for another 14 days (recovery phase). The third piece was transferred during the assay period into a sepa- rate, amphipod-free Petri dish (see next paragraph) to measure autogenic changes in wet mass and returned to EUs after assays were terminated. At the end of the recovery phase, the same algal piece was used again to measure autogenic changes in wet mass during assays. The remaining two algal pieces were withdrawn from EUs to assess their palatability levels in multi-choice feeding assays of either live pieces or agar-based food (testing for reduction of the defence after treatment).

\section{Feeding preference assays}

Two-way choice (July experiment) or multiple-choice (September experiment) feeding assays compared the relative palatability of differently treated algal pieces. In the July experiment, one live piece of a control and a grazed alga were offered to amphipods simultaneously in a Petri dish $(15 \mathrm{~cm} \varnothing)$ for 4 days. The water in Petri dishes was exchanged every $12 \mathrm{~h}$. In the September experiment, 4 differently treated algal pieces each (see above) was offered in the same Petri dish. For distinction during the feeding assays, algal pieces were coded by coloured threads. In the multiple-choice assay with artificial food, the pellets were individualized by different incision patterns. Different amphipod individuals were used in the treatment phase and in subsequent feeding assays to avoid consumer adaptations. Wet mass of assayed algal pieces was measured to the nearest $0.001 \mathrm{~g}$ at the beginning and end of feeding assays. Moreover, the wet mass change of a control algal piece from the same treatment as the assayed alga was used to correct consumption rates for non-feeding-related autogenic changes in wet mass, according to the Peterson and Renaud (1989) formula:

consumption $=T_{\text {start }} \times\left(C_{\text {end }} / C_{\text {start }}\right)-T_{\text {end }}$

where $T_{\text {start }}$ and $T_{\text {end }}$ represent pre- and post-assay wet mass of pieces of an assayed alga, respectively, and $C_{\text {start }}$ and $C_{\text {end }}$ represent pre- and post-assay wet mass of autogenic control pieces, respectively.

\section{Preparation of artificial food}

To determine whether the induced defences were due to secondary metabolites (activated or induced only for defensive purposes), feeding assays with lipophilic algalextracts were performed for those algae that showed significant responses in assays using live algal pieces. Algal pieces were submerged in $10 \mathrm{ml}$ of dichloromethane for 2 day at room temperature. Subsequently, the dichloromethane supernatant was poured onto Ulva lactuca powder and allowed to evaporate. In this manner, the Ulva powder was coated by the non-polar algal compounds. Ulva has 
been used previously as a standard food, palatable to most herbivores, in assays using algal extracts (e.g. Deal et al. 2003). A mixture of $0.72 \mathrm{~g}$ Agar and $10 \mathrm{ml}$ distilled water was boiled, allowed to cool to ca. $40^{\circ} \mathrm{C}$, mixed with the algal compound-coated Ulva powder, and poured over a mosquito mesh flattened between two fibreglass panels (method adapted from Hay et al. 1994). After cooling, a $15 \times 15 \mathrm{~mm}^{2}$ section was cut from each pellet and used in feeding assays.

\section{Statistical analysis}

Consumption rates from choice feeding assays (July experiment) were analysed by two-tailed paired $t$-tests. Prior to statistical analyses, the normal distribution of differences between control and grazed alga pieces was confirmed with the Kolmogorov-Smirnov test. Consumption rates from multiple-choice feeding assays (September experiment only) were analysed by resampling without replacement, using a Monte Carlo analysis with 10,000 permutations (Bärlocher 1999). Pairwise $t$-tests were used as post-hoc tests, for which no Bonferroni correction was calculated, if the probability of finding that the number of significant $t$-tests by chance was below 5\% (Moran 2003).

\section{Results}

July experiment

At the end of the treatment phase, live specimens of Gelidium, Sphaerococcus, and Dictyopteris showed a non-significant trend of higher palatability in control pieces than in amphipod-attacked pieces (all paired $t$-test: $t_{4} \leq 1.85$, $P>0.05)$. Only for live Fucus pieces, amphipod consumption of control pieces was significantly higher (by $60 \%$ on average) than consumption of amphipod-attacked pieces (paired $t$-test: $t_{4}=4.83, P=0.008$, Fig. 1 ). This pattern was also detected when agar-based food containing lipophilic Fucus-extracts was used. Control pieces were significantly preferred by $31 \%$ over agar-based food containing lipophilic extracts from amphipod-attacked conspecifics (paired $t$-test: $t_{4}=4.67, P=0.01$, Fig. 2).

\section{September experiment}

The experiment was performed with Fucus, the only species that had shown a significant reduction in palatability in response to amphipod attacks.

1. Live Fucus: At the end of the 2-week treatment phase, amphipod consumption was significantly different between differently treated Fucus pieces (resampling,

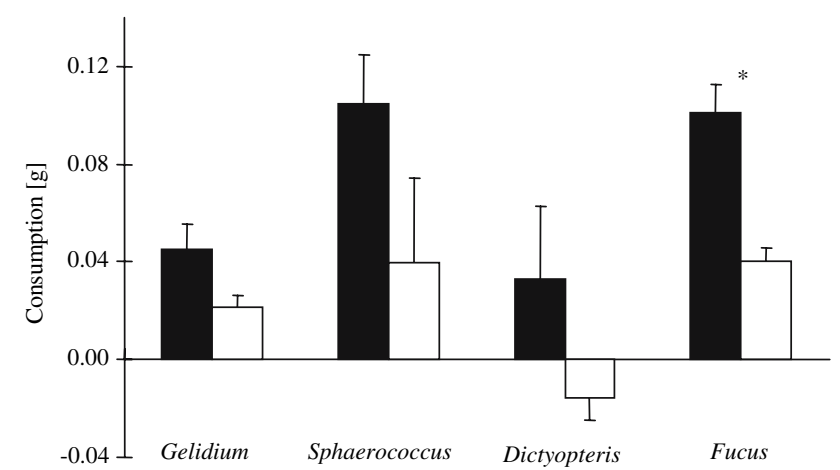

Fig. 1 Mean (+SE) amphipod-consumption on live pieces of different alga species during 4-day long feeding assays $(n=5)$ at the end of the treatment phase (see "Materials and methods" for details). Black bars controls, open bars directly amphipod attacked, * significantly different

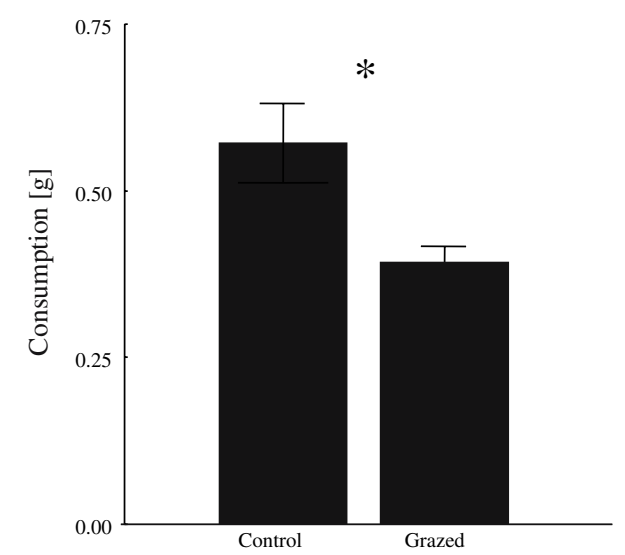

Fig. 2 Mean (+SE) amphipod-consumption of artificial Fucus vesiculosus food during 4-day long feeding assays $(n=5)$ at the end of the treatment phase (see "Materials and methods" for details). * Significantly different

$P=0.019)$. The palatability of individuals exposed to water-borne cues from nearby amphipod-grazed conspecifics and/or grazing amphipods, as well as to nongrazing amphipods, was significantly lower than the palatability of control pieces, while the palatability of directly grazed Fucus pieces was non-significantly decreased (Fig. 3a). Control pieces were on average $48 \%$ more palatable than grazed pieces. At the end of recovery phase, the palatability of Fucus controls increased even more. Control pieces were on average a significant $91 \%$ more consumed than Fucus pieces exposed to the other three treatments (resampling $P=0.050$ ).

2. Agar based food containing lipophilic Fucus-extracts. At the end of both treatment and recovery phase, amphipod consumption was not significantly affected by grazing treatments (resampling: treatment phase $P=0.137$, recovery phase $P=0.561$; Fig. $3 b$ ). 

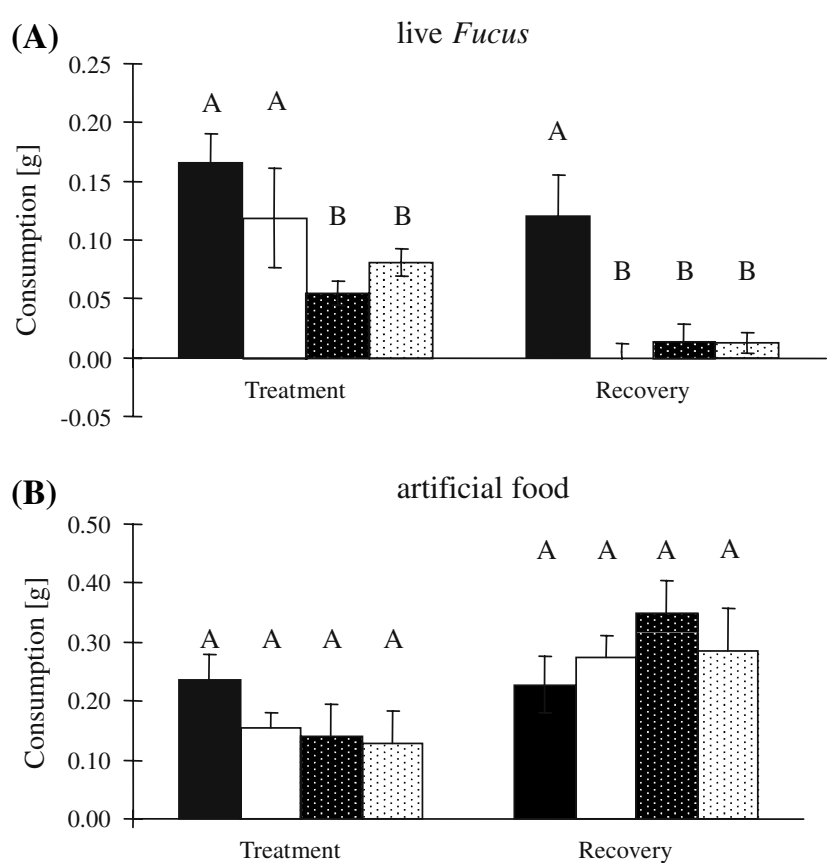

Fig. 3 Mean (+SE) amphipod-consumption on Fucus vesiculosus during 4-day long feeding assays $(n=7)$ at the end of the treatment and recovery phase (see "Materials and methods" for details) for a live algae and b agar-based food containing lipophilic Fucus-extracts. Treatments sharing the same letter are not significantly different. Black bars control, open bars directly amphipod attacked, white dotted bars waterborne cues from nearby-grazed conspecifics, black dotted bars waterborne cues from non-grazing amphipods

\section{Discussion}

In all algae species tested in the July experiment, control pieces were preferred over grazed pieces, but this was statistically significant only for Fucus. Also in the case of assays using artificial food containing lipophilic Fucusextracts, control pieces were preferred over directly grazerexposed pieces. As shown in the September experiment, exposure of Fucus to water-borne cues from nearby compartments containing either amphipods grazing on Fucus or amphipods alone, also reduced the palatability of live alga pieces but not that of artificial food containing a respective alga extract. A change in palatability of grazed Fucus may theoretically also occur if the consumers removed the more palatable parts of the alga, leaving less palatable portions untouched. However, this seems unlikely because amphipods consumed only a small fraction, i.e. $<5 \%$, of Fucus wet mass during the treatment phase. In addition, control pieces of Fucus continued to be more palatable than grazed pieces even after grazing had ceased for 14 days and new tissues had been formed. Alternatively, this change in palatability suggests that direct amphipod grazing induced an anti-herbivore response of morphological and/or chemical origin. In addition, the significant reduction in consumption of artificial food containing extracts of amphipod-attacked Fucus, hints at an induced production or mobilization of lipophilic, i.e. non-phlorotannin, compounds with anti-herbivory effects. An induction of chemical anti-herbivory compounds in brown seaweeds has been reported by several studies (e.g. Rohde et al. 2004). The role of phlorotannins has been well studied in this context, but results are controversial. Algal palatability after induction of phlorotannins stimulated (Pavia et al. 1997), decreased, or did not affect (Pavia and Toth 2000) seaweed consumption by the mesograzers Littorina $o b$ tusata or Idotea granulosa. Also, even at elevated concentrations, phlorotannins lack repulsive effects against at least some mesograzers, including amphipod species (Kubanek et al. 2004). The rigorous bioassay guided study of Deal et al. (2003) revealed that F. vesiculosus compounds, which were repulsive to urchins, were neither within the phlorotannin- nor the DCM-soluble fraction. According to the present study, and contrary to Deal et al. (2003), an amphipod repulsive compound seems to occur primarily in the lipophilic fraction of the Fucus-chemistry. In addition to chemical defences, amphipods may induce morphological anti-herbivory defences in Fucus. An induction of morphological defences has been described for other Fucus species. For example, F. distichus generates adventitious branches in response to the attack of littorine snails (van Alstyne 1989). We did not observe the production of new tissues, but cannot rule out that Fucus induced less obvious morphological changes, e.g. tissue toughness or blade shape (Lowell et al. 1991; Ruuskanen and Back 1999), for which no measurements were taken. But morphological defences-if induced-were in any case not the only ones, since a (slightly smaller) anti-herbivory activity was also found in the extracts.

Inductive patterns were altered in two ways when experiments were repeated later in the year. On the one hand, anti-herbivory defences were detected with some delay in live Fucus, i.e. only at the end of the recovery phase, and on the other hand effects were not detected with artificial food containing lipophilic Fucus-extracts. It could be speculated that the delayed inductive response may result from a seasonally variable herbivore activity. For example, Fucus sensitivity to amphipod grazing may change seasonally, due to differential allocation of defensive compounds in response to seasonal performance for growth and reproduction. Second, seasonal differences in amphipod abundance are known to affect grazing pressure on algae (e.g. Worm 2000), but these data are missing for our study site. Finally, amphipod activities are temperature-dependent. Decreasing water temperature lowers grazing rates in molluscs, isopods, or urchins (Jonne et al. 2006). In the present study, temperature dropped an almost negligible $2^{\circ} \mathrm{C}$ between the July and the September 
experiments, making temperature-dependent effects on amphipod grazing unlikely. Seasonal differences in the inducibility of anti-herbivory defences were rarely investigated, but reported for the kelp Ecklonia cava (Molis et al. 2006). Here water temperature had been identical across seasons, suggesting that factors other than temperature drove changes in repulsive responses in Ecklonia cava. The second deviation from the July experiment, i.e. lacking effects in assays using artificial food containing lipophilic Fucus-extracts, is interesting. This may be due to changes in the identity of effective algal anti-herbivory compounds across seasons. Phenotypic plasticity is expected to lower the risk of consumer co-evolution (Agrawal and Karban 1999). If algae vary the kind of anti-herbivore compounds in combination with plastic responses, the risk of co-evolving consumers should be further lowered compared to inducing always the same defensive compound, as consumers need to adapt (1) to different defence molecules that are (2) not constantly present in the food.

Amphipods consumed significantly less tissue from Fucus-specimens located down-stream of nearby grazed conspecifics than from control algae. This suggests an induction of anti-herbivory defences by water-borne cues, which has been already shown for three species of macroalgae, including F. vesiculosus (Pavia and Toth 2000; Rohde et al. 2004; Macaya et al. 2005). At the collection site, Fucus grows in dense stands. This facilitates the action of water-borne cues, which confer to Fucus conspecifics information about impending grazing (Rohde et al. 2004). Our study extents existing evidence about water-borne induction responses in Fucus driven by isopod grazers to amphipods. In contrast to the study by Rohde et al. (2004) dealing with isopod grazers, the present study indicates that water-borne info-chemicals released by the amphipod grazer alone, induced anti-herbivory defences in Fucus. Water-borne cues from mere grazer presence were generally considered as a deficient signal to induce stronger response to grazer attacks (van Alstyne 1988; Toth and Pavia 2000; Rohde et al. 2004) rather than direct and nearby grazing. However, our study reveals that Fucus may be sensitive to even non-grazing amphipods. This algal susceptibility to amphipods alone is surprising because amphipods use Fucus also as a habitat. Thus, Fucusspecimens should permanently receive the inducing cue, which should lead to a permanent induction, i.e. a de facto constitutive defence. According to Karban et al. (1999), this quasi-constitutive response should minimise for the algae the selective advantage of using water-borne cues from non-grazing herbivores to induce anti-herbivory defences. Dissipation and dilution of cues emitted by the amphipods were possible much lower in our experimental units than in the natural environment. Possibly, this leads to cue concentrations, which in the field, would signal particularly high amphipod densities. Alternatively, Fucus may benefit from the ability to initiate defences as soon as the first signals of a strong grazer density are perceived, if amphipod abundances fluctuate sharply, resulting in sudden changes of grazing pressure. Testing this hypothesis requires identification of signal thresholds as well as seasonal monitoring of amphipod abundance. Finally, widespread induction response by Fucus should increase the number of distasteful conspecifics, which in turn may increase amphipod movements among algae, increasing amphipod visibility to their predators (Borell et al. 2004).

In conclusion, the effectiveness of lipophilic compounds as well as speed and strength of inducible anti-herbivory defences were variable in time. This variation adds complexity to algae-mesoherbivore interactions, because inducible algae remain at least to a certain extend part of herbivore's diet rather than constitutively defended algae. Therefore, inducible defence could possibly advance stability in benthic systems similar to what is known from planktonic systems (Verschoor et al. 2004).

Acknowledgments We are grateful for indispensable help by Ester Serrao. Financial support by Stiftung Mercator to MW is acknowledged.

\section{References}

Agrawal AA, Karban R (1999) Why induced defenses may be favored over constitutive strategies in plants. In: Tollrian R, Harvell C (eds) The ecology and evolution of inducible defenses. Princeton University Press, Princeton, pp 45-61

Bärlocher F (1999) Biostatistics. Thieme Verlag, Stuttgart

Borell EM, Foggo A, Coleman RA (2004) Induced resistance in intertidal macroalgae modifies feeding behaviour of herbivorous snails. Oecologia 140:328-334

Brawley S (1992) Mesoherbivores. In: John S, Hawkins S, Price J (eds) Plant-animal interactions in the marine benthos. Clarendon Press, Oxford, pp 235-263

Brawley SH, Adey WH (1981) The effect of micrograzers on algal community structure in a coral reef microcosm. Mar Biol 61:167-177

Cronin G (2001) Resource allocation in seaweeds and marine invertebrates: chemical defense patterns in relation to defense theories. In: McClintock JB, Baker BJ (eds) Marine chemical ecology. CRC, Boca Raton, pp 325-353

Cyr H, Pace ML (1993) Magnitude and patterns of herbivory in aquatic and terrestrial ecosystems. Nature 361:148-150

Deal MS, Hay ME, Wilson D, Fenical W (2003) Galactolipids rather than phlorotannins as herbivore deterrents in the brown seaweed Fucus vesiculosus. Oecologia 136:107-114

Duffy JE, Hay ME (2000) Strong impacts of grazing amphipods on the organization of a benthic community. Ecol Monogr 70:237263

Hay ME (1991) Marine-terrestrial contrasts in the ecology of plant chemical defenses against herbivores. TREE 6:362-365

Hay ME (1996) Marine chemical ecology: what's known and what's next? J Exp Mar Biol Ecol 2000:103-134 
Hay ME, Fenical W (1988) Marine plant-herbivore interactions: the ecology of chemical defense. Annu Rev Ecol Syst 19:111-145

Hay ME, Duffy JE, Pfister CA, Fenical W (1987) Chemical defense against different marine herbivores: are amphipods insect equivalents? Ecology 68:1567-1580

Hay ME, Kappel QE, Fenical W (1994) Synergisms in plant defenses against herbivores-interactions of chemistry, calcification, and plant-quality. Ecology 75:1714-1726

Hemmi A, Honkanen T, Jormalainen V (2004) Inducible resistance to herbivory in Fucus vesiculosus - duration, spreading and variation with nutrient availability. Mar Ecol Prog Ser 273:109-120

Jonne K, Helen OK, Tiina P, Ilmar K, Henn K (2006) Seasonal changes in situ grazing of the mesoherbivores Idotea baltica and Gammarus oceanicus on the brown algae Fucus vesiculosus and Pylaiella littoralis in the Central Gulf of Finland, Baltic Sea. Hydrobiologia 554:117-125

Karban R, Baldwin IT (1997) Induced response to herbivory. University of Chicago Press, Chicago

Karban R, Agrawal AA, Thaler JS, Adler LS (1999) Induced plant responses and information content about risk of herbivory. TREE 14:443-447

Kubanek J, Lester SE, Fenical W, Hay ME (2004) Ambiguous role of phlorotannins as chemical defenses in the brown alga Fucus vesiculosus. Mar Ecol Prog Ser 277:79-93

Lowell RB, Markham JH, Mann KH (1991) Herbivore-like damage induces increased strength and toughness in a seaweed. Proc R Soc Lond Ser B Biol Sci 243:31-38

Macaya EC, Rothausler E, Thiel M, Molis M, Wahl M (2005) Induction of defenses and within-alga variation of palatability in two brown algae from the northern-central coast of Chile: effects of mesograzers and UV radiation. J Exp Mar Biol Ecol 325:214 227

Molis M, Korner J, Ko YW, Kim JH, Wahl M (2006) Inducible responses in the brown seaweed Ecklonia cava: the role of grazer identity and season. J Ecol 94:243-249

Moran MD (2003) Arguments for rejecting the sequential Bonferroni in ecological studies. Oikos 100:403-405
Myers RA, Worm B (2003) Rapid worldwide depletion of predatory fish communities. Nature 423:280-283

Pavia H, Toth GB (2000) Inducible chemical resistance to herbivory in the brown seaweed Ascophyllum nodosum. Ecology 81:32123225

Pavia H, Cervin G, Lindgren A, Aberg P (1997) Effects of UV-B radiation and simulated herbivory on phlorotannins in the brown alga Ascophyllum nodosum. Mar Ecol Prog Ser 157:139-146

Peterson CH, Renaud PE (1989) Analysis of feeding preference experiments. Oecologia 80:82-86

Rohde S, Molis M, Wahl M (2004) Regulation of anti-herbivore defence by Fucus vesiculosus in response to various cues. J Ecol 92:1011-1018

Ruuskanen A, Back S (1999) Morphological variation of northern Baltic Sea Fucus vesiculosus L. Ophelia 50:43-59

Taylor RB, Sotka E, Hay ME (2002) Tissue-specific induction of herbivore resistance: seaweed response to amphipod grazing. Oecologia 132:68-76

Toth GB, Pavia H (2000) Water-borne cues induce chemical defense in a marine alga (Ascophyllum nodosum). Proc Natl Acad Sci USA 97:14418-14420

Toth GB, Pavia H (2001) Water borne chemical cues as elicitors of algal defenses. J Phycol 37:49

van Alstyne KL (1988) Herbivore grazing increases polyphenolic defenses in the intertidal brown alga Fucus distichus. Ecology 69:655-663

van Alstyne KL (1989) Adventitious branching as a herbivoreinduced defense in the intertidal brown alga Fucus distichus. Mar Ecol Prog Ser 56:169-176

Verschoor AM, Vos M, Van der Stap I (2004) Inducible defences prevent strong population fluctuations in bi- and tritrophic food chains. Ecol Lett 7:1143-1148

Worm B (2000) Consumer versus resource control in rocky shore food webs: Baltic Sea and Northwest Atlantic Ocean. Dissertation, University of Kiel, Germany 